\title{
A Web-Based Recommender System for end-of-use ICT Products
}

\author{
Angelika I. Kokkinaki ${ }^{1}$, Rommert Dekker ${ }^{2}$, Nikos Karacapilidis ${ }^{3}$, Costas \\ Pappis $^{4}$ \\ 1)Econometrics Institute, Erasmus University Rotterdam, P.O. Box 1738, NL-3000 DR \\ Rotterdam, The Netherlands \\ Phone: +3110408 1416, Fax: +31104089162 \\ E-mail: kokkinaki@few.eur.nl \\ 2)Econometrics Institute, Erasmus University Rotterdam, P.O. Box 1738, NL-3000 DR \\ Rotterdam, The Netherlands \\ Phone: +31 10408 1274, Fax: +31 104089162 \\ E-mail: rdekker@few.eur.nl \\ 3)Industrial Management Lab, MEAD, University of Patras, GR 26504 Rion-Patras, Greece \\ Phone: +30610 997257, Fax: +30610997260 \\ E-mail:nikos@mech.upatras.gr \\ 4)Department of Industrial Management, University of Piraeus, GR 18534 Piraeus, Greece \\ Phone: +30 10 4142150, Fax: +30104142328 \\ E-mail:pappis@unipi.gr
}

\begin{abstract}
Original Equipment Manufacturers in the Information and Communication Technology sector have recently started to prioritize management of their returns for several reasons. Effective management of returns is a complicated problem due to the uncertainty related to the quantity, quality, timing and place of origin of returns. Exploring the case of end-of-use PCs, this paper describes a web-based system, namely Reverse Logistics Marketplace, in which the interested parties, delegate tasks related to management of returns to software agents, instead of carrying out physical operations. PC users, interested in returning their PCs or their parts, can access the e-marketplace using the PC in request and call for a "trusted-third-party" agent to perform configuration detection and benchmarking of their PC. Potential buyers can also access the e-marketplace to register their collection requests, regarding either complete PCs or modules of them. Advanced features of the system include the permanent existence of agents in the e-marketplace to learn from conducted transactions, their ability to act proactively to initiate a transaction,
\end{abstract}

\footnotetext{
The original version of this chapter was revised: The copyright line was incorrect. This has been corrected. The Erratum to this chapter is available at DOI: 10.1007/978-0-387-35617-4_48 
and the integration of a multiple-criteria decision support tool that performs a comparative evaluation of the collection requests and recommends the optimal recovery option to the $\mathrm{PC}$ users.

Keywords: Reverse Logistics, Software Agents, Electronic Marketplace

\section{INTRODUCTION}

Returns of Information and Communication Technology (ICT) equipment, including obsolete or near-obsolete inventory, discarded used products or commercial returns have received increasing attention recently. The major factors contributing to that are the following:

- Legislative frameworks: The EU Directive on Waste of Electrical and Electronic Equipment (WEEE) requires Original Equipment Manufacturers (OEMs) to develop a policy for the collection and reuse of ICT products at the end of their life cycle. This Directive aims to shift waste management costs to producers, reduce volume of generated waste and increase use of recycled materials.

- Environmental impact: End-of-use ICT equipment is recognized as a serious environmental threat. In USA, the Environmental Protection Agency ranks end-of-use PCs as the fastest growing category of solid waste. Furthermore, end-of-use computers contain heavy metals; thus, if they are simply disposed in a landfill they impose environmental threats.

- Asset Recovery: Industry-wide, annual costs related to returns are estimated to $\$ 15$ billion (Bayles, 2001). Instead of a liability, returns can be a source for value recovery by re-using the return (possibly in a secondary market), remanufacture its parts to be used as spares or recycling the remaining to recover the materials value.

Thus, effective management of ICT returns becomes a priority in the strategic agenda of OEMs; the cases of IBM and Dell are presented in (Kokkinaki et. al., 2002). To manage returns flows, reverse logistics networks are developed, which typically include operations for collection, selection and decision making for the optimal recovery option (reuse, remanufacture, recycle). For example, an end-of-use PC can be dismantled in modules that can be directly reused as spares (i.e., CD ROM, hard disks, keyboard etc.) or remanufactured into new products (chips used in electronic toys), while all the remaining can be recycled to regain its materials value. In general, effective returns management becomes very difficult due to the high uncertainty associated with quantity, quality, place of origin, and timing of returns. More specifically, ICT returns present some additional challenges: 
- High devaluation rate; this requires an effective and speedy redistribution of returns in the original market (customers returns) or in secondary markets (excess inventory).

- End-users' reluctance to release their ICT equipment; this presents a burden for optimal recovery. Thus, an effective mechanism needs to be designed and implemented to pull these units back from the endusers in a timely manner.

- Capture of assessment data is delayed; these data become available only when the units are actually retrieved. However, exploitation of new information technologies can support the earlier capture of this information.

In this paper, we address issues related to the problem of effective returns management and explore how the web technologies can be used to lower the uncertainty regarding quantity, quality, place of origin and timing of returns. For that, we have developed an agent-based framework within the context of an electronic marketplace that enables interested users to perform configuration detection and benchmarking of their PCs remotely, just by connecting them to the Internet and accessing the proposed marketplace. Upon users' confirmation, data regarding the quantity, configuration and place of origin of end-of-use PCs are registered in the system's database as a new offer. Prospective buyers can view offers and contact the related sellers directly to finalize a transaction. Buyers can also access the e-marketplace to register their collection requests, regarding either complete PCs or modules of them. Agents exchange messages encapsulating offers and requests of the trading parties, while the system integrates mechanisms for matching the above offers and requests. Moreover, buyers may get instantly aware of each incoming offer and tailor their request according to them.

From a business perspective, the proposed system is very appealing, because it lowers transaction costs and automates several, previously manual, operations. Furthermore, it offers a trustworthy mechanism for configuration detection and quality assessment. Even more important, it provides a cohesive platform that de-fragmentizes the returns market and releases trapped value. From an IT perspective, the proposed system maintains profiles for all potential buyers (through the personalization of the agents involved) to give recommendations in alignment with their interests and preferences. Also, agents may take the initiative to contact their actors when they identify a seemingly interesting transaction. Third, seller agents in this system may perform a progressive synthesis and comparative evaluation (across a set of attributes) of the existing requests. This requires a highly interactive tool, based on multiple criteria decision theory, that enables customers examine alternative scenarios (by selecting which of the attributes of the matched requests to be taken into account) and recommends the best 
recovery options, concerning reuse, remanufacturing or recycling, according to the information at hand.

These are the main contributions of this paper, which is structured as follows: Section 2 presents the overall e-marketplace architecture, focusing on the protocols used for communication and collaboration between the system's (human and software) agents. Section 3 provides a more detailed presentation of all agent types of the system and illustrates their constituent modules. Finally, Section 4 concludes the paper by discussing related work and outlining directions for future research.

\section{THE OVERALL ARCHITECTURE}

The overall architecture of the proposed e-marketplace adopts the ModelView-Controller design pattern (Buschmann et al., 2001). In our implementation, the View object is a standard web browser, the Model object is a RDBMS, while the application Controller object has been implemented in Java (software agents, Java Servlets and Java Server Pages). The electronic marketplace is decomposed into the following subsystems:

- Repository: holds all application data. The persistent storage of the repository is guaranteed by the use of a relational database system. All textual data are stored in Unicode format.

- Application Server: accepts/process all HTTP requests.

- Security: controls system access in conjunction with the Java Cookie technology.

- Mailer: sends a notification to the appropriate recipients of the system, every time a new request or offer has been successfully submitted.

- Presenter: presents the appropriate Java Server Page (JSP) or html according to the user status (registered or not registered) and request.

A detailed presentation of the developed system can be found in (Kokkinaki et. al., 2001). In this paper, we focus on the agents' architecture and the configuration detection and benchmarking mechanism.

\subsection{Features}

The proposed system builds on a set of communicating agents that act on behalf of the related actors (i.e., interested sellers and buyers) and perform a 
series of tasks for them (Figure 1). Actors are logged in the system, "hire" their personal agents (by paying subscription fees that depend on the time they want them to "live"), create a profile for them, and launch them in the e-market. A potential seller may initiate a configuration request; this triggers a trusted-third-party agent to perform configuration detection and benchmarking of the PC currently used to access the e-marketplace. Upon sellers' agreement, the information on the screened PC is registered in the system's repository and it is marked as a new offer. Potential buyers (i.e., OEMs or recyclers) can register their collection intentions as requests. Requests can be issued either for entire PC units or single PC modules. The system integrates mechanisms to match the above offers and requests. In addition, potential buyers may be instantly notified about incoming offers. Whenever a match is identified, the corresponding seller is notified through the mail services of the system. Then, the seller may launch an agent to comparatively evaluate all requests retrieved.

An agent's profile serves its personalization; that is, actors can provide their agents with their general interests, preferences and constraints. For potential buyers, specification of the market segment and sets of services sought are usually included in their profiles. For example, a potential buyer specifies hard disks and processors in his/her general interests. Furthermore, he/she states that he/she prefers the Intel family to the AMD one and sets as a constraint for the hard disks to have capacity greater than 20GB. As another example, an interested seller can specify to his/her agent as a general interest to achieve the best possible price, but he/she prefers to trade with Non Governmental Organizations (schools, volunteer groups, etc). Finally, expressing his/her constrains, he/she may exclude requests from other countries. The above "general" knowledge is updated, refined and enriched with each subsequent transaction. For instance, a buyer agent may update its

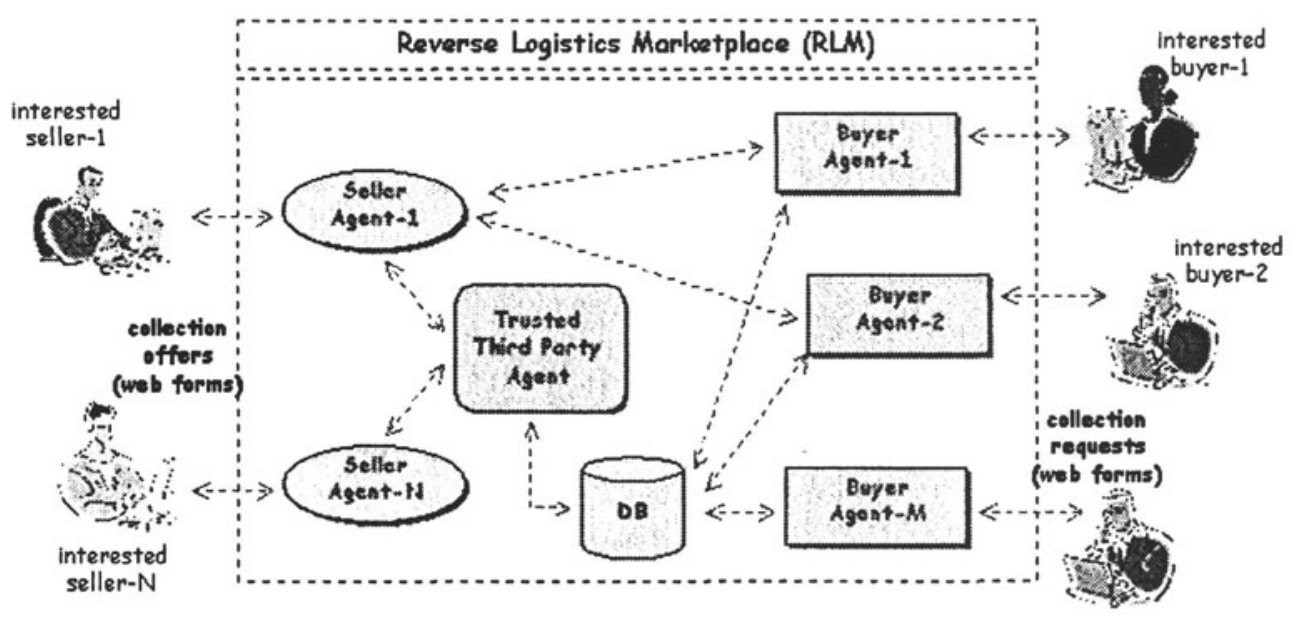

Figure1: The overall e-marketplace framework 
profile every time it reads the system's repository or performs certain transactions, in order to be able to identify regular customers (that is, trading partners who have conducted two or more transactions) and send them special offers in the future.

Transactions in our e-marketplace can be initiated either by human actors or by software agents. Interested sellers, who have been notified that some requests match their offer by the system's mailing services, may launch an agent that performs a comparative evaluation of all relevant requests; such an agent may interact with them in order to arrive at an optimal decision. System's agents are proactive and semi-autonomous, so, they can also initiate transactions. More specifically, a buyer agent whose profile matches to a seller's offers takes the initiative to contact its actor and ask his/her opinion to proceed if an interesting offer has been inserted in the system's repository (note that buyer agents are continuously monitoring the system's database). In a similar way, a buyer agent, when noticing that the market's seller agents continuously discard its requests due to their prices, can suggest its actor to modify them.

Whenever a match is established, the customer may launch a seller agent and provide it with information about the actor's buying criteria, preferences and constraints. Having access to this information, a buyer agent is able to build an offer that is as close as possible to the seller's profile. In Figure 1, we illustrate a case in which both buyer_agent-1 and buyer_agent-2 are interested in the offer submitted by seller-1; so, they communicate with seller_agent-1 and tailor their offers. More specifically, before responding to a seller agent's request, each buyer agent would have tailored its offer according to the information at hand (that is, information submitted by the seller agent) and its actor's range of interests. Having collected a bunch of such offers, a seller agent has to consider and evaluate them all with the aim to recommend the best one to its actor.

The functional specifications of the proposed e-marketplace also include efficient handling of the registration of the users involved and appropriate emailing services. The data flow diagram illustrated in Figure 2 provides a summary of the processes and actors involved (due to space limitations, a detailed analysis of each process cannot be given in this paper). As shown, there are three types of software agents involved, namely buyer agent, seller agent and trusted-third-party (TTP) agent, while the system's repository keeps track of the users and products registered in the system.

\subsection{Communication among actors}

To establish the cooperation protocol described above, agents communicate by exchanging messages of various types. Each message type conveys certain semantics associated with a particular task of a transaction. 
When an agent receives a message, it knows immediately what reasoning procedure must be activated to deploy the most appropriate answer or action (if required) to the message received, or what kind of update it has to perform in its domain specific knowledge. In other words, each message type characterizes a pair of interacting players (interested sellers, seller agents, ttp agent, buyer agents, and interested buyers) and a specific type of interaction.

A typical interaction among the system's agents is schematically represented in Figure 3, whereas the messages involved are analytically described in Table 1. It should be noted here that the list of these messages is not exhaustive; rather, it corresponds to the basic transactions carried out among the actors of the marketplace.

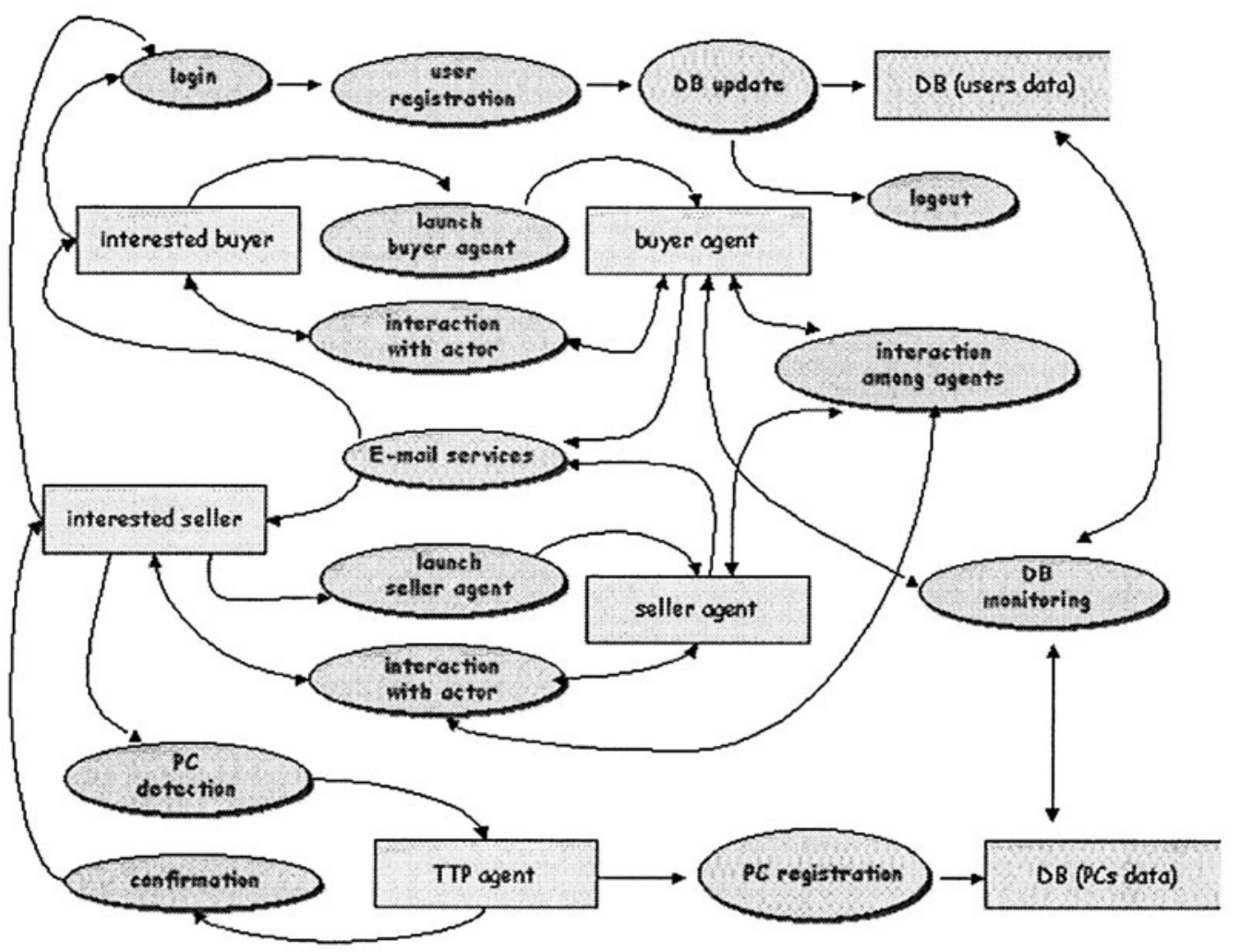

Figure 2: Actors and processes in the e-marketplace 


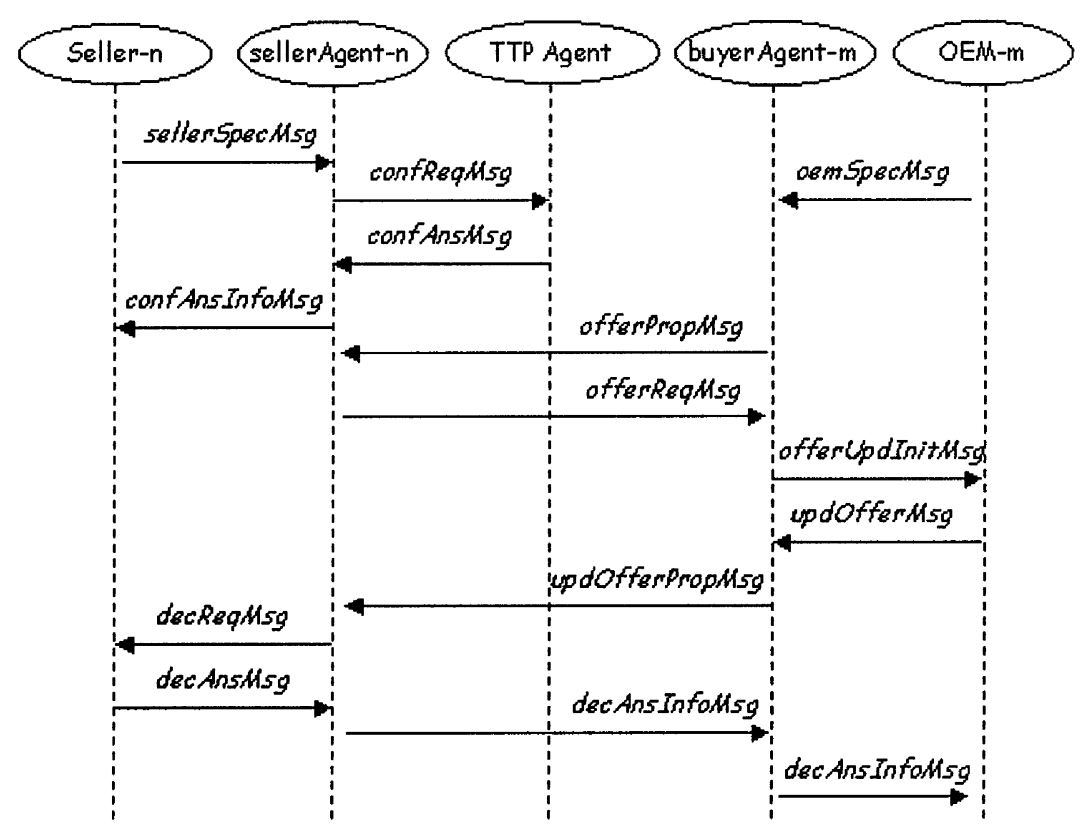

Figure 3: Interactions in the e-marketplace

\begin{tabular}{|l|c|c|l|}
\hline Message & Sender & Receiver & \multicolumn{1}{|c|}{ Description } \\
\hline sellerSpecMsg & $\begin{array}{l}\text { interested } \\
\text { seller }\end{array}$ & sellerAgent & $\begin{array}{l}\text { It describes the } \\
\text { profile of interested } \\
\text { seller }\end{array}$ \\
\hline confReqMsg & sellerAgent & ttpAgent & $\begin{array}{l}\text { They concern the } \\
\text { interaction between } \\
\text { the seller and the ttp } \\
\text { agent for detecting } \\
\text { the PC's components. }\end{array}$ \\
\hline offerReqMsg & ttpAgent & sellerAgent & $\begin{array}{l}\text { It conveys the } \\
\text { interested seller's PC } \\
\text { specifications. }\end{array}$ \\
\hline offerPropMsg & sellerAgent & buyerAgent & $\begin{array}{l}\text { It is the reply to a } \\
\text { collection offer (see } \\
\text { previous message } \\
\text { type). }\end{array}$ \\
\hline offerUpdInitMsg & buyerAgent & sellerAgent & $\begin{array}{l}\text { Sent when a buyer } \\
\text { agent proposes to his } \\
\text { actor to update an } \\
\text { existing offer. }\end{array}$ \\
\hline bupdOfferMsg & interested & buyer & $\begin{array}{l}\text { Sent when an } \\
\text { interested buyer } \\
\text { wants to update an } \\
\text { existing offer. }\end{array}$ \\
\hline
\end{tabular}




\begin{tabular}{|l|c|c|l|}
\hline updOfferPropMsg & BuyerAgent & sellerAgent & $\begin{array}{l}\text { It concerns an } \\
\text { updated collection } \\
\text { proposal (see two } \\
\text { previous message } \\
\text { types). }\end{array}$ \\
\hline decReqMsg & sellerAgent & $\begin{array}{l}\text { interested } \\
\text { seller }\end{array}$ & $\begin{array}{l}\text { They concern the } \\
\text { proactive interaction } \\
\text { between a seller } \\
\text { agent and his actor to } \\
\text { investigate interest } \\
\text { on a proposal by a } \\
\text { buyer agent }\end{array}$ \\
\hline decAnsMsg & interested seller & sellerAgent & $\begin{array}{l}\text { It informs the buyer } \\
\text { agent about the } \\
\text { seller's decision. }\end{array}$ \\
\hline oemSpecMsg & sellerAgent & buyerAgent & $\begin{array}{l}\text { It describes an } \\
\text { interested buyer's } \\
\text { profile and collection } \\
\text { requests. }\end{array}$ \\
\hline
\end{tabular}

Table 1: Messages passed in the e-marketplace

\section{SOFTWARE AGENTS}

In the proposed e-marketplace, three types of software agents have been developed. They follow a generic architecture, which has been already tested and evaluated in another agent-mediated e-commerce system (Karacapilidis and Moraitis, 2001a; 2001b). The agent types in this e-marketplace are composed of three modules, which run concurrently and intercommunicate by exchanging internal messages (i.e., intra-agent messages), as shown in Figure 4. However, their constituent modules are tailored, according to the agent's type. For instance, a buyer agent usually has a less elaborated decision making module than a seller agent.

The communication module of an agent is responsible for the agent's interaction with its environment, including other software agents and the human user it assists. It sends and receives messages, while internally interacts with the coordination module. Its functionality can be briefly described as follows: an internal receiver transforms each internally queued message (produced by the coordination module) to an inter-agent message and stores it to the outgoing messages queue. In case of selective or point-topoint communications, it adds the receiving agent's address. An external receiver handles the opposite, by transforming each external message received to an internal one and adding it to the incoming messages queue. Finally, a message transmitter monitors the incoming and outgoing queues 
and dispatches the queued messages to its coordination module, other agents or to its human user, accordingly.

The coordination module handles the parts of the cooperation protocol that concern any type of interaction with its environment (for a list of the corresponding messages, refer to Table 1). In addition, the coordination module keeps track of the agent's finished tasks and the tasks under evolution (e.g., a collection offer evaluation for a specific item can be momentary suspended due to the search for supplementary information). As shown in Figure 4, the module interacts with the communication and the decision-making modules. When the decision making module needs to interact with the actor, it first sends a message to the coordination module which, in turn, attaches additional information (if required) and forwards it to the communication module. Similarly, the coordination module may filter the content of a received message before forwarding the related data to the decision-making module. In many cases, an agent has to access its database, which contains all necessary information about its actor. A database entry for a buyer agent may contain information its actor's profile and other features. Based on this data and exploiting the decision-making module described in the sequel, a buyer agent is aware of which sellers it has to contact and send a collection request.

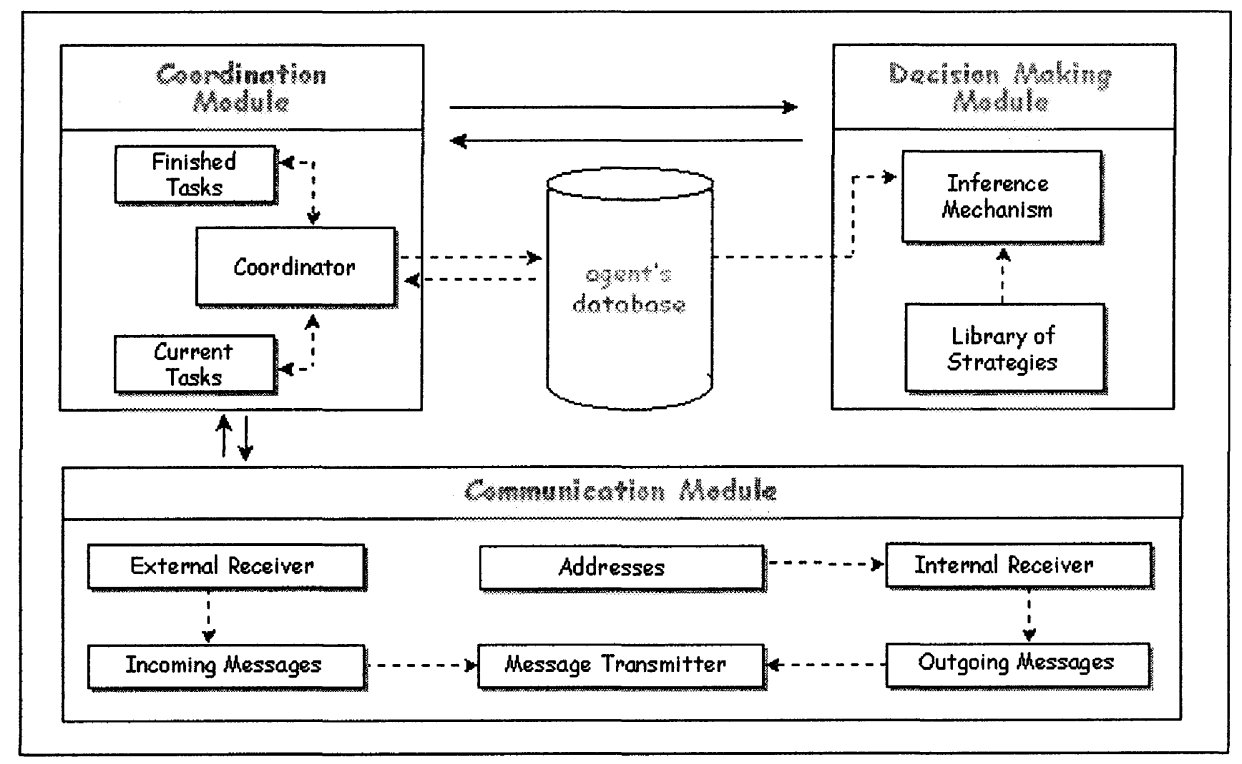

Figure 4: Architecture of agents

The decision-making module has two basic components, namely, an inference mechanism and a library of strategies. It deploys the agent's 
reasoning mechanism that implements the proactive behaviour of the agent; this is thoroughly described in (Karacapilidis and Moraitis, 2001a). For the trusted-third-party agent, the module integrates the trial version of "PC examiner". Figure 5 depicts a snapshot of the user interface after this tool has been initiated.

In progress research concerns the integration of a multiple criteria decision making tool, allowing the progressive synthesis and comparative evaluation of the collection proposals, in the decision-making module of seller agents. The tool implemented for the automation of this process is an extension of the work described in (Karacapilidis and Papadias, 1998). Briefly, the tool enables a potential seller to weigh alternative collection proposals. It evaluates them according to his/her sets of criteria, features, preferences and constraints with the aim to decide about the best recovery option of his/her PC or its modules. Criteria represent broader evaluation metrics, that is, metrics that may stand for more than one purchase categories; (e.g. cost, performance, etc.), while features concern specific attributes of a criterion which usually depend on the specific product to be collected. Preferences provide a means to weigh pairs of criteria or features.

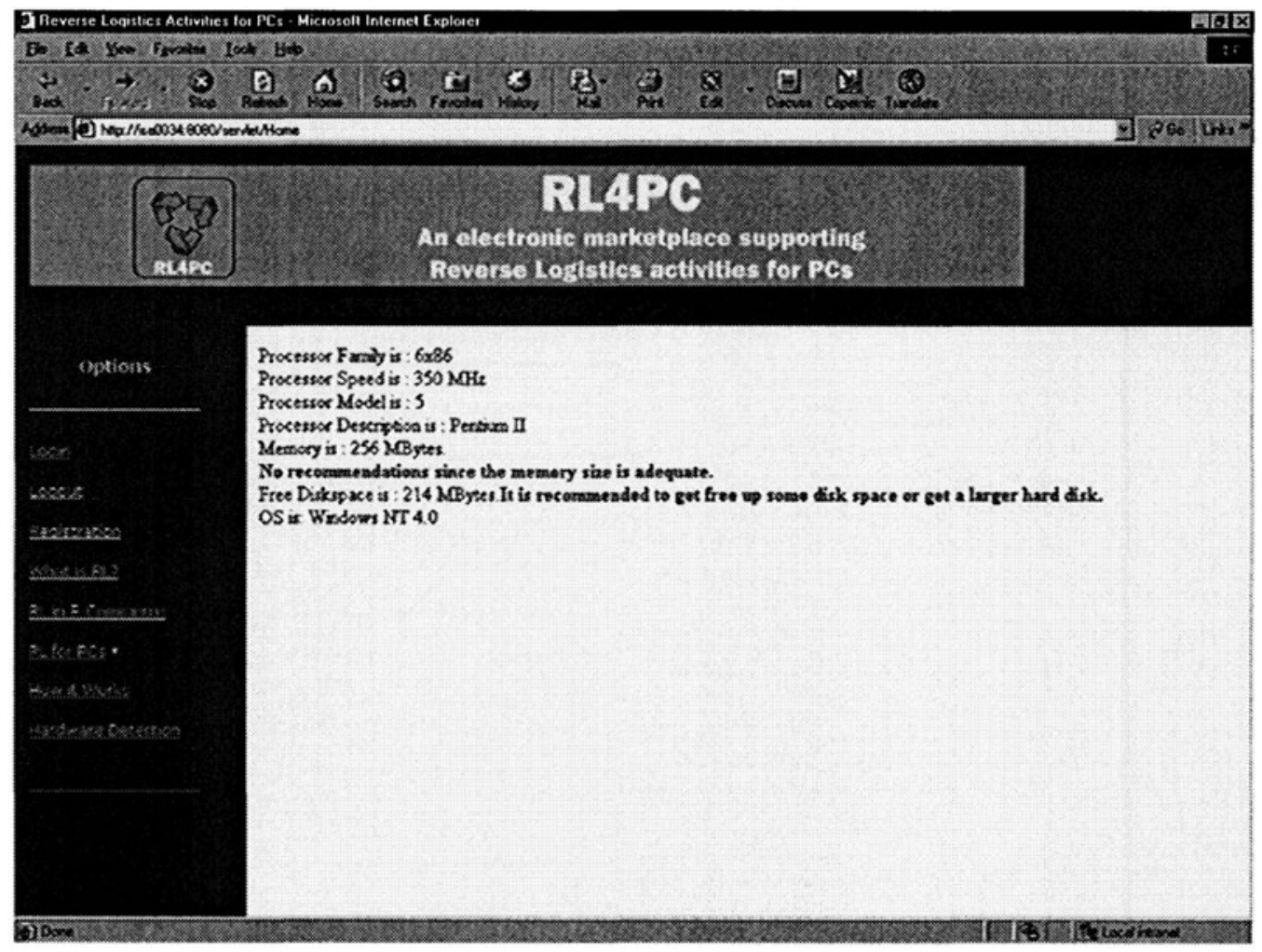

Figure 5: User interface - results of PC configuration 
They are represented by tuples of the form (criterion, impRel, criterion) or (feature, impRel, feature), where impRel $\in$ (more(less)_important_than, equally_important_to]. Finally, constraints provide a way to express a user's wish about the value a certain feature should possess. For the PC case, (processor, belongs, Intel_family) and (price, more_than, \$120) can be such data types.

\section{DISCUSSION}

Developing and employing web technologies to collect and process information on the characteristics of end-of-use returns is effectively an open research topic, which has recently received some interesting contributions. A thorough overview of existing IT systems for end-of-use products can be found in (Krikke et al., 2001), while (Hillegersberg et al., 2001) has outlined some of the functional and technical requirements for IT systems supporting integrated returns management. Internet-based technology is also potentially far reaching in supporting new organizational forms and new ways of coworking with public and private organizations that lead towards new ebusiness models for reverse logistics, as documented in (Kokkinaki et al., 2002). Experiments on the impact of information in electronic auctions for recycled electronics showed mixed results on the final profits, as outlined in (Ryan et al., 2001). A more detailed description of the allocation mechanism used in these auctions can be found in (Olafsson et al., 2001). Related to this topic, (Gemmill et al., 2001) have examined the predisposition of actors in reverse logistics networks regarding sharing of information.

Software agents technology has been applied in a diversity of tasks associated to the purchasing or selling of goods and services in an electronic market (Bakos, 1998; Nwana et al., 1998; Schmid and Lindemann, 1998). It is widely argued that the today's success of agent-mediated electronic commerce in creating new markets and reducing various transaction costs will be boosted by the displacement of the current buying and selling processes with new business models (Froehlich et al., 1999). As concluded in a recent survey (Guttman et al., 1998), such a change will take place as software agent technologies come to better deal with issues such as the ambiguity of content, personalization of preferences, complexity of goals, and dynamics of the related environments.

In this paper, we exploit prominent characteristics of software agents, such as autonomy, proactiveness and "intelligence", together with their ability to cooperate, in order to delegate reverse supply chain transactions to them. We have demonstrated that the proposed approach lowers the uncertainty associated with returns and, as a result, contributes to more efficient and effective returns management systems. Our web-based system 
is fully implemented in Java. Agents communicate using TCP/IP, while actors interact with them through user-friendly web interfaces. We point out that the proposed system is the first to apply software agents technology in the context of a reverse logistics and address its unique features.

In the future, we plan to examine how this approach can be extended to address the installed base of ICT equipment and their recovery options within a large organization. In that respect, additional requirements regarding users access rights and privacy should be also considered. Moreover, we would like to examine the integration of an elaborated negotiation stage by exploiting a multicriteria-based negotiation model; for a comprehensive overview of such models, see (Lo and Kersten, 1999). Negotiation on a set of product features, for instance, between a purchaser and a seller agent, will enable the former better tailoring its proposal and, eventually, work more efficiently for its actor.

Further to the development of optimal recovery policies for ICT supply chains, and following the concepts illustrated in this paper, we also plan to work on the development of advanced services for products with embedded intelligent control and wireless communication systems. This can open new directions for research and applications in the field of m-business and reverse logistics. Interesting examples of such services include the proactive and reactive maintenance of vehicles (Mercedes Benz TeleAid system, USA), electrical equipment (OTIS elevators, The Netherlands) and smart home appliances (Whirpool refrigerators, USA).

\section{ACKNOWLEDGEMENT}

Research presented in this paper has been supported by the European Commission as part of the TMR Network REVLOG (EBR 4061 Pl 97-650). This network investigates reverse logistics issues and is a cooperation of researchers from Erasmus University Rotterdam (NL), Eindoven University of Technology (NL), INSEAD (F), University of Piraeus (GR), University of Magdeburg (D) and Aristotle University of Thessaloniki (GR). For more information, refer to $w w w . f b k . e u r . n / / O Z / R E V L O G$

\section{REFERENCES}

Bakos, Y. Towards Friction-Free Markets: The Emerging Role of Electronic Marketplaces on the Internet, Communications of the ACM 1998; 8: 35-42

Bayles, Deborah, E-commerce Logistics and Fulfilment: Delivering the Goods, Upper Saddle River, NJ: Prentice Hall, 2001. 
Buschmann, Frank, Meunier, Regine, Rohnert, Hans, Sommerland, Peter, Stal, Michael, Pattern Oriented Software Architecture (A System of Patterns), John Wiley and Sons Ltd., 2001.

Froehlich, G., Hoover, H.J., Liew, W., Sorenson P. Application Framework Issues when Evolving Business Applications for Electronic Commerce, Information Systems 1999; 6: 457-473

Gemmill D., Quamhiyah, A., Ryan, S. Electronics Manufacturers' Support for Product Recycling. Proceedings of the $10^{\text {th }}$ Annual Industrial Engineering Research Conference; 2001; Dallas, USA.

Guttmann, R., Moukas, A.G., Maes, P. Agent-Mediated Electronic Commerce: A Survey, Knowledge Engineering Review 1998; 2:147-159

van Hillegersberg, J., Zuidwijk, R., van Nunen, J., van Eijk D. Supporting Return Flows in the Supply Chain, Communications of the ACM 2001; 6:74-79

Karacapilidis, N., Moraitis, P. Building an Agent-Mediated Electronic Commerce System with Decision Analysis Features. Decision Support Systems 2001, 1: 53-69

Karacapilidis N., Moraitis P. Intelligent Agents for an Artificial Market System. Proceedings of the 5th Int. Conference on Autonomous Agents; 2001 May 28 - June 1; Montreal, Canada: ACM Press, New York, 592-599

Karacapilidis N., Papadias D. Hermes: Supporting Argumentative Discourse in Multi-Agent Decision Making. Proceedings of the 15th National Conference on Artificial Intelligence; 1998, Madison, WI, AAAI/MIT Press, 1998; 827-832

Kokkinaki, A.I., Dekker, R., Lee, R., Pappis, C. Integrating a Web-based System with Business Processes in Closed Loop Supply Chains, Econometric Institute Report Series EI2001-31, 2001; Erasmus University Rotterdam, ISSN 1566-7294, The Netherlands.

Kokkinaki, A.I., Dekker, R., de Koster, M.B.M., Pappis, C., Verbeke W. E-business models for reverse logistics: contributions and challenges, Proceedings IEEE Computer Society (ITCC) International Conference on Information Technology; 2002 8-10 April; Las Vegas, Nevada.

Krikke, H., Kokkinaki A.I., van Nunen J. "Information Technology in Closed Loop Supply Chains", In Business Aspects of Closed Loop Supply Chains, V.D.R. Guide Jr., L.N. Van Wassenhove eds., Carnegie Mellon University Press.

Lo, G., Kersten, Gr. Negotiation in Electronic Commerce: Integrating Negotiation Support and Software Agent Technologies. Proceedings of the 29th Atlantic Schools of Business Conference; 1999; Halifax, NS, 1999.

Nwana, H., Rosenschein, J., Sandholm, T., Sierra, C., Maes, P., Guttmann, R. AgentMediated Electronic Commerce: Issues, Challenges and some Viewpoints, Proceedings of Autonomous Agents; 1998; ACM Press, 189-196

Olafsson, S., Min, K.J., Subramaniam, G., Sulakhe, S., Varghese S., and Yang J. InternetBased management and Archival System for Recyclable Products. Proceedings of the $10^{\text {th }}$ Annual Industrial Engineering Research Conference; 2001; Dallas, USA.

Ryan, S., Min, K.J., Olafsson, S., "Experimental Study of Scalability Enhancement for Reverse Logistics E-Commerce." In Scalable Enterprise Systems, V. Prabhu, S. Kumara, M. Kamath eds, 2001.

Schmid, B. and Lindemann, M. Elements of a Reference Model for Electronic Markets, Proceedings of HICCS '98; 1998; Hawaii, USA, 193-201 